\title{
Correction to: Dietary protein intake and subsequent risk of type 2 diabetes: a dose-response meta-analysis of prospective cohort studies
}

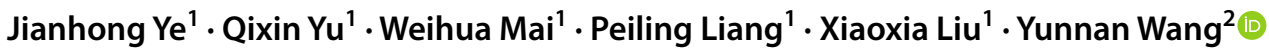

Published online: 30 May 2019

(c) Springer-Verlag Italia S.r.l., part of Springer Nature 2019

\section{Correction to: Acta Diabetologica \\ https://doi.org/10.1007/s00592-019-01320-x}

The article Dietary protein intake and subsequent risk of type 2 diabetes: a dose-response meta-analysis of prospective cohort studies written by Jianhong Ye, Qixin Yu, Weihua Mai, Peiling Liang, Xiaoxia Liu, Yunnan Wang was originally published electronically on the publisher's internet portal (currently SpringerLink) on 30 March 2019 with open access. With the author(s)' decision to step back from Open Choice, the copyright of the article changed on 30 May 2019 to (C) Springer-Verlag Italia S.r.l., part of Springer Nature 2019 and the article is forthwith distributed under the terms of copyright.

The original article has been corrected.
The original article can be found online at https://doi.org/10.1007/ s00592-019-01320-x.

Yunnan Wang

fszyyyjh@163.com

1 Department of Endocrinology, Foshan Hospital of TCM, Foshan 528000, China

2 Functional Department, Foshan Hospital of TCM, No.6 Qinren Road, Chancheng District, Foshan 528000, China
Publisher's Note Springer Nature remains neutral with regard to jurisdictional claims in published maps and institutional affiliations. 